\title{
Association of some rare haplotypes and genotype combinations in the MDRl gene with childhood acute lymphoblastic leukaemia
}

\author{
Ágnes F. Semsei ${ }^{\mathrm{a}}$, Dániel J. Erdélyi a ${ }^{\mathrm{a} b}$, Ildikó Ungvári ${ }^{\mathrm{a}}$, Enikő Kámory ${ }^{\mathrm{c}}$, Béla Csókay ${ }^{\mathrm{c}}$, \\ Hajnalka Andrikovics ${ }^{\mathrm{d}}$, Attila Tordai ${ }^{\mathrm{d}}$, Edit Cságoly ${ }^{\mathrm{a}}$, András Falus ${ }^{\mathrm{a}}$, \\ Gábor T. Kovács ${ }^{b}$, Csaba Szalai e,f,* \\ a Department of Genetics, Cell- and Immunobiology, Semmelweis University, Budapest, Hungary \\ b 2nd Department of Paediatrics, Semmelweis University, Budapest, Hungary

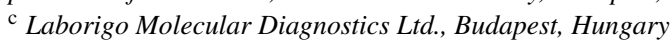 \\ d Department of Molecular Diagnostics, National Medical Center, Budapest, Hungary \\ e Inflammation biology and Immunogenomics Research Group, Hungarian \\ Academy of Sciences - Semmelweis University, Budapest, Hungary \\ ${ }^{\mathrm{f}}$ Heim Pal Pediatric Hospital, Budapest, Hungary
}

Received 17 October 2007; received in revised form 19 December 2007; accepted 20 December 2007 Available online 19 February 2008

\begin{abstract}
To investigate their possible roles in disease susceptibility and some disease characteristics we genotyped C3435T and G2677T/A polymorphisms in multidrug resistance-1 (MDR1) gene with a single base extension method and the G34A and C421A polymorphisms of the breast cancer resistance protein gene with an allelic discrimination system in 396 children with acute lymphoblastic leukaemia (ALL) and 192 control patients. While the distribution of individual alleles and genotypes did not differ between patients and controls, there were significant differences in the frequencies of some rare haplotypes and genotype combinations in the MDRl gene between the two groups.
\end{abstract}

(c) 2007 Elsevier Ltd. All rights reserved.

Keywords: MDR1; ABCB1; BCRP; ABCG2; SNP; Haplotype; Genotype; Disease susceptibility; Acute lymphoblastic leukaemia; Hyperdiploidity

\section{Introduction}

Acute lymphoblastic leukaemia (ALL) is a clonal disease of a lymphoblast and the most common malignancy of all childhood cancers. It is generally accepted that tumorogenesis results from complex interplay between inherited genetic background and specific environmental exposure [1].

The multidrug resistance-1 (MDR1, also referred to as $\mathrm{ABCB} 1)$ gene belongs to the ATP-binding cassette (ABC) family and encodes for membrane transporter P-glycoprotein (P-gp) [2]. P-gp is expressed in several tissues and cells,

\footnotetext{
* Corresponding author at: Heim Pal Pediatric Hospital, P.O. Box 66, H1958, Budapest, Hungary. Tel.: +36 14599 100/1365; fax: +36 14599165 .

E-mail addresses: szalai@ heimpalkorhaz.hu, szalaics@gmail.com (C. Szalai).
}

among others it is expressed by CD34+ haematopoietic stem cells [3]. One of the physiological roles of P-gp is the protection of the organism against toxic xenobiotics. A proportion of xenobiotics transported by P-gp is associated with mutagen activity [4]. It can be hypothesized that genetically based differences may result in varying exposure to environmental carcinogens, with lower activity linked to increased risk of malignancy. Several polymorphisms were identified in the MDRl gene. The most widely studied single nucleotide polymorphism (SNP) is the C3435T silent transition in exon 26, which in some studies was found to be associated with altered duodenal expression of Pgp and altered substrate specificity and transporter activity $[5,6]$. The C3435T SNP was found to be in significant linkage disequilibrium with other SNPs, including the G2677T polymorphism in exon 21, resulting in Ala893Ser and also associating with lower P-gp activity [7]. The roles of these 
Table 1

Some clinical and biologic characteristics of ALL patients of this study and of all children from the Hungarian Paediatric Cancer Registry diagnosed with ALL between 1990 and 2002

\begin{tabular}{|c|c|c|c|}
\hline & & $\begin{array}{l}\text { Cases in this } \\
\text { study }(n=396)\end{array}$ & $\begin{array}{l}\text { All cases from the Hungarian Paediatric Cancer Registry } \\
\text { diagnosed with ALL between } 1990 \text { and } 2002(n=776)\end{array}$ \\
\hline Age at diagnosis & $\begin{array}{l}1-10 \text { years } \\
<1 \text { year } \\
>10 \text { years }\end{array}$ & $\begin{array}{c}316(79.8) \\
5(1.3) \\
75(18.9)\end{array}$ & $\begin{array}{c}578(74.5) \\
22(2.8) \\
176(22.7)\end{array}$ \\
\hline Sex & $\begin{array}{l}\text { Male } \\
\text { Female }\end{array}$ & $\begin{array}{l}216(54.5) \\
180(45.5)\end{array}$ & $\begin{array}{l}442(57.0) \\
334(43.0)\end{array}$ \\
\hline Risk group & $\begin{array}{l}\text { HR } \\
\text { MR } \\
\text { LR }\end{array}$ & $\begin{array}{r}46(11.6) \\
252(63.6) \\
98(24.8)\end{array}$ & $\begin{array}{l}124(16.0)^{*} \\
458(59.0)^{*} \\
185(23.8)^{*}\end{array}$ \\
\hline Relapse & $\begin{array}{l}\text { No } \\
\text { Yes }\end{array}$ & $\begin{array}{r}334(84.8) \\
60(15.2)\end{array}$ & $\begin{array}{l}622(80.2) \\
154(19.8)\end{array}$ \\
\hline Died & $\begin{array}{l}\text { No } \\
\text { Yes }\end{array}$ & $\begin{array}{r}331(83.6) \\
65(16.4)\end{array}$ & $\begin{aligned} & 539(69.5) \\
& 237(30.5)^{* *}\end{aligned}$ \\
\hline Immunophenotype & $\begin{array}{l}\mathrm{B} \text { lineage } \\
\mathrm{T} \text { lineage }\end{array}$ & $\begin{array}{r}291(84.6) \\
53(15.4)\end{array}$ & $\begin{array}{l}530(82.4)^{* * * *} \\
113(17.6)^{* * * *}\end{array}$ \\
\hline
\end{tabular}

Values are given as $n(\%)$. Abbreviations: HR: high risk; MR: medium risk; LR: low risk.

* 9 patients were unclassified or unknown regarding risk group.

** $P<0.001$.

*** No data available in case of 133 patients.

SNPs in the risk to ALL are quite controversial. Some studies found an association between 3435 TT genotype and increased susceptibility to childhood ALL, while others did not $[8,9,10]$.

The breast cancer resistance protein (BCRP, also known as $\mathrm{ABCG} 2$ ) is a recently described $\mathrm{ABC}$ transporter originally identified by its ability to confer drug resistance that is independent of P-gp [11]. The normal function of BCRP may be to prevent the accumulation of extra- and intracellular toxins in cells [12]. An early clue to the importance of BCRP was the fact that its expression in haematopoietic cells is greater than that of MDR1, suggesting its crucial role in protecting these cells from toxic xenobiotics [13]. The two most frequently identified SNPs in the BCRP gene are in exon 2 (G34A, resulting in a V12M change) and exon 5 (C421A, resulting in a Q141K substitution). Although the exact functions of these variants have not yet been established, some studies indicate that the $421 \mathrm{~A}$ allele is less functional, suggesting a possible role of this variant in the susceptibility to haematological malignancies, including ALL [14].

In this study, we investigated whether the presence of these polymorphisms was associated with ALL and whether any of these alleles influenced some disease characteristics and the outcome of the therapy in the affected individuals. As it is widely accepted, the haplotype structures or allelic associations can be more predictive than individual SNPs; we also studied the effect of estimated haplotypes and genotype combinations on the above-mentioned features.

\section{Methods}

\subsection{Study population and definitions}

In a retrospective manner, DNA was obtained from 396 children (mean age at diagnosis: $6.1 \pm 3.9$ years) who underwent chemotherapy due to acute lymphoblastic leukaemia. Patients were diagnosed with ALL between 1990 and 2002, aged 1-15 years at diagnosis and treated in ten Hungarian centres. According to the data of the Hungarian Paediatric Cancer Registry, 776 children were diagnosed ALL in Hungary in the given time period, therefore our cohort contains $51.0 \%$ of all patients. See Table 1 to compare the rate of subpopulations. There is no significant difference in the distribution of age groups or genders or ALL-immunophenotypes between the whole population and our sample-collection. Our sample set contains similar rate of relapsed patients to what was observed in the whole population. However, the rate of died patients is significantly lower in our study population $(P<0.001)$. This is because a large proportion of relapsed patients survive or if die then die many years after diagnosis so we could collect samples from many such patients. Patients who died during the chemotherapy due to therapy resistant progressive disease or due to infections or toxicities of therapy are underrepresented in our sample.

In most cases DNA was extracted from peripheral blood taken in 2003 and 2004 in haematologic remission $(n=331)$. From patients who died before our sample-collection period, DNA was obtained from bone marrow smears $(n=65$, prepared at diagnosis or in remission). 
The 192 control patients (95 male and 97 females; aged $36.8 \pm 10.5$ years) of the same ethnicity and from the same geographical region as the patients were randomly selected from healthy blood donors. None of the controls have had childhood ALL or any other types of cancers previously.

All study subjects belonged to the Hungarian (Caucasian) population. Informed consent was requested from the study subjects, or from the parents of patients. The study was approved by the Ethics Committee of the Hungarian Medical Research Council.

\subsection{Laboratory methods}

Genomic DNA from blood was extracted using the QIAmp Blood DNA Maxi Kit (Qiagen) and from smears with the HighPure PCR Template Preparation Kit (Roche Diagnostics) according to the manufacturers' instructions.

The MDR1 C3435T, and G2677T, a genotypes were determined by a single base extension method based on that published by Gwee et al. [15] with several minor alterations as described earlier [16]. BCRP G34G and C421A genotyping was performed using the LightCycler (Roche Diagnostics) allelic discrimination system as described previously [17]. All genotypes were determined at least twice. Only those genotypes were accepted, when at least two genotypings gave the same results.

Genotype findings were verified on two samples for each genotype by single PCR followed by bidirectional sequencing using the BigDye v3.1 kit on an ABI310 sequencer.

\subsection{Statistical methods}

Allele frequencies were calculated by allele counting. Data were analyzed using MedCalc 5.0 and SPSS 11.5 programs. Hardy-Weinberg equilibrium was tested by using a $\chi^{2}$ goodness-of-fit test. $\chi^{2}$ test was used to test for differences in allele distribution between the groups. Logistic regression adjusted for age and sex was applied to assess the effect of the genetic background to dichotomous clinical characteristics. Confidence intervals were calculated at the 95\% level. Estimated haplotype frequency was calculated by haploview: http://www.broad.mit.edu/mpg/haploview/ [18]. Haplotype-specific ORs were estimated using conditional logistic regression to model the log odds of disease as a function of the individuals' haplotype probabilities.

\section{Results}

Table 2 shows the prevalence of the polymorphisms in patients with ALL and in healthy control subjects. No significant differences were observed in genotype or allele frequencies between cases and controls. The genotype distribution was overall in Hardy-Weinberg equilibrium.

Table 3 shows the estimated haplotype frequencies in cases and controls in the MDRI and BCRP genes in respect

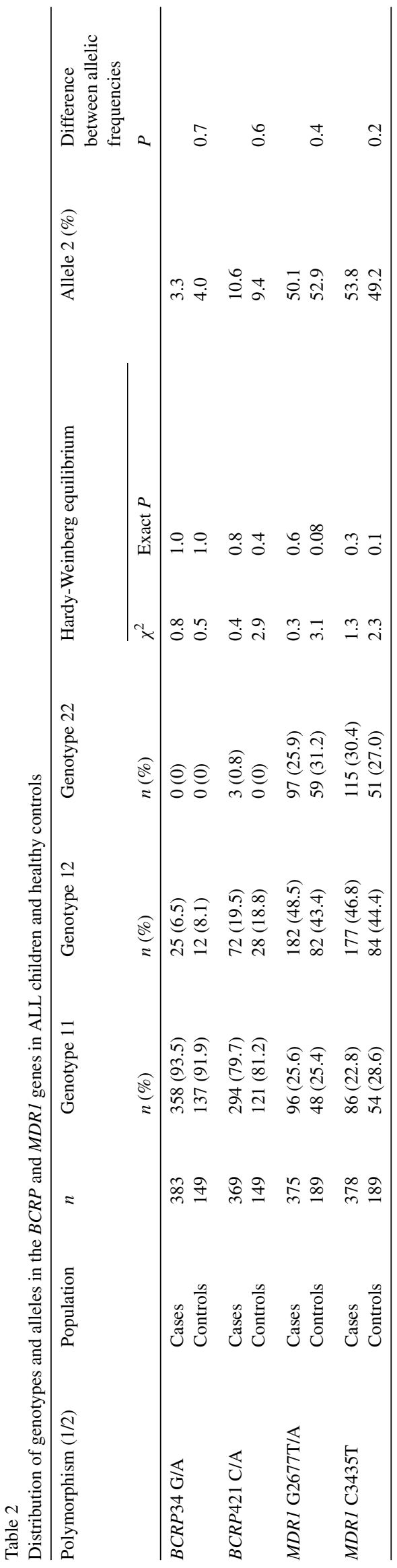


Table 3

Estimated haplotype frequencies in the MDR1 and BCRP genes in the two populations

\begin{tabular}{lccl}
\hline Haplotypes & ALL children (\%) & Controls (\%) & $P$-values \\
\hline \multicolumn{2}{l}{ MDR1 G2677T/A, C3435T } & & \\
TT & 44.4 & 45.3 & 0.8 \\
GC & 43.2 & 44.1 & 0.8 \\
GT & 9.4 & 3.9 & $0.002^{\mathrm{a}}$ \\
TC & 3.0 & 6.7 & $0.006^{\mathrm{b}}$ \\
BCRP G34A, C421A & & \\
GC & 86.1 & 86.6 & 1.0 \\
GA & 10.6 & 9.4 & 0.8 \\
AC & 3.3 & 4.0 & 0.9 \\
\hline
\end{tabular}

a $\mathrm{OR}=2.5(1.4-4.4)$.

b $\mathrm{OR}=0.4(0.2-0.8)$.

of G2677T/A, C3435T and G34A, C421A polymorphisms, respectively. While no significant differences were found in the prevalence of the two predominant haplotypes (TT and GC) in the MDRl gene between cases and controls, there were significant differences in the frequencies of the two rarer haplotypes. The GT haplotype was more frequent in cases $(9.4 \%$ versus $3.9 \% ; P=0.002$; odds ratio $(\mathrm{OR})=2.5(95 \%$ confidence interval 1.4-4.4)), while the TC haplotypes were more prevalent in controls ( $3.0 \%$ versus $6.7 \% ; P=0.006$; $\mathrm{OR}=0.4$ $(0.2-0.8))$. The haplotype distribution did not differ between the two groups in the $B C R P$ gene. These data indicate that GT haplotype in the $M D R 1$ gene might associate with increased, while TC haplotypes with decreased susceptibility to ALL.

We calculated also the linkage disequilibrium coefficients $\left(\mathrm{D}^{\prime}\right)$ between the alleles: MDR1 G2677T and C3435T: 0.6; G2677A and C3435T: 0.04; BCRP G34A and C421A: 0.004 (in both controls and cases). As these results show there is a linkage between the G2677T and C3435T alleles, while there is no such connection in the other two cases.

Next the distributions of the genotype combinations were compared in the two genes in ALL patients and controls. As can be seen in Table 4A, there are two genotype combinations of the positions 2667 and 3435 in the MDR1 gene which occurred more frequently in ALL patients: GT/TT, (8.73\% versus $3.17 \%$, in patients and controls, respectively; $P=0.02 ; \mathrm{OR}=2.88(1.19-7.11))$; and GG/CT $(7.41 \%$ versus $2.65 \% ; P=0.04$; $\mathrm{OR}=2.97(1.12-7.77))$. Furthermore, genotype combination of TT/CT was more frequent in controls $(2.12 \%$ versus $7.94 \% ; P=0.002 ; \mathrm{OR}=0.26(0.11-0.61)$. The distribution of the genotype combinations in the BCRP gene did not differ significantly between cases and controls.

Subsequently it was investigated whether these alleles, haplotypes and genotype combinations influence the clinical characteristics of ALL. None of these genetic factors showed association with age at diagnosis, sex, immunophenotype, risk group, relapse and leukaemia related death (data not shown). As Urayama et al. [9] found statistically increased risk to hyperdiploid ALL ( $>50$ chromosomes) in a small subgroups $(n=27)$ of white non-Hispanic Caucasian ALL patients with some MDRl genotypes and a haplotype, we also carried out this analysis in our patients. In our patient group there were 78 children with hyperdiploid ALL, but this chromosomal aberration showed no association with any of the genotypes or haplotypes. Patients with 2677TA/TT/AA had OR $=0.5(0.3-1.1)$; those of with 3435TT had OR $=0.7$ (0.4-1.3), or with TT haplotype had OR $=0.5(0.3-1.1)$ for hyperdiploid ALL.

\section{Discussion}

Acute lymphoblastic leukaemia is a multifactorial disease influenced by genetic and environmental factors. In this study, we investigated whether potentially functional polymorphisms in genes coding $\mathrm{ABC}$ transporters responsible for protection of the organisms against environmental carcinogens might alter the susceptibility to childhood ALL or influence some disease characteristics or the outcome of the therapy in the affected individuals. In our population, we have found that individual polymorphisms in the $M D R 1$ and $B C R P$ genes do not change the risk for developing the disease, but the distributions of some haplotypes and genotype combinations in the MDRl gene differed significantly between ALL children and healthy controls.

It must be noted, however, that this study might have some limitations. One of them is that our study population is biased as patients who died before our sample-collection period are underrepresented, thus it is possible that the conclusion of this study might be modified if all the patients were involved. Furthermore, although we have matched our patient and control groups for sex and ethnicity, the two populations differ significantly in age. But we do not think that this would influence our conclusion significantly. Allele and genotype frequencies in our study in both patients and controls are very similar to other published child and adult Caucasian populations $[8,9]$. In addition, although it is not possible to totally exclude, but seems very implausible that children and adults with the same ethnicity and from the same environment would differ significantly just because of their age in haplotype distributions in genes like $M D R I$ and $B C R P$. In addition, none of the controls had childhood ALL, thus we think, they were appropriate for negative controls.

Until now, three studies have been published about the role of MDRl polymorphisms in the susceptibility to childhood ALL. Jamroziak and Robak [8] in a study of 113 Caucasian cases and Hattori et al. [10] in 157 Japanese patients found an association between 3435 TT genotype and ALL, while Urayama et al. [9] studying 135 non-Hispanic Caucasian cases did not find such association. Hattori et al. also found an association when analysed haplotypes involving three polymorphisms in the $5^{\prime}$ regulatory region (not involving the 3435 alleles) of the MDRl gene. Urayama et al. also investigated MDRI haplotypes, but found no association. Our study involved the largest number of Caucasian ALL children $(n=396)$, but was unable to confirm the association between MDR1 3435 TT genotype and ALL, but found that certain haplotypes and genotype combinations in the MDRI 
Table 4

Numbers and percentage of some genotype combinations in the $M D R l(\mathrm{~A})$ and $B C R P(\mathrm{~B})$ genes

\begin{tabular}{|c|c|c|c|c|c|}
\hline \multirow[t]{2}{*}{ G2677T/A/C3435T } & \multicolumn{2}{|c|}{ ALL children $(n=378)$} & \multicolumn{2}{|c|}{ Controls $(n=189)$} & \multirow[t]{2}{*}{$P$ values } \\
\hline & $n$ & $\%$ & $n$ & $\%$ & \\
\hline \multicolumn{6}{|l|}{ (A) } \\
\hline GT/CT & 126 & 33.33 & 59 & 31.22 & 0.7 \\
\hline $\mathrm{TT} / \mathrm{TT}$ & 76 & 20.11 & 42 & 22.22 & 0.6 \\
\hline $\mathrm{GG} / \mathrm{CC}$ & 66 & 17.46 & 42 & 22.22 & 0.2 \\
\hline GT/TT & 33 & 8.73 & 6 & 3.17 & $0.02^{\mathrm{a}}$ \\
\hline $\mathrm{GG} / \mathrm{CT}$ & 28 & 7.41 & 5 & 2.65 & $0.04^{\mathrm{b}}$ \\
\hline GT/CC & 9 & 2.38 & 9 & 4.76 & 0.2 \\
\hline $\mathrm{TT} / \mathrm{CT}$ & 8 & 2.12 & 15 & 7.94 & $0.002^{\mathrm{c}}$ \\
\hline $\mathrm{AG} / \mathrm{CC}$ & 8 & 2.12 & 3 & 1.59 & 0.9 \\
\hline $\mathrm{AG} / \mathrm{CT}$ & 7 & 1.85 & 5 & 2.65 & 0.8 \\
\hline $\mathrm{AT} / \mathrm{CT}$ & 6 & 1.59 & 0 & 0.00 & 0.2 \\
\hline \multirow[t]{2}{*}{ G34A/C421A } & \multicolumn{2}{|c|}{ ALL children $(n=366)$} & \multicolumn{2}{|c|}{ Controls $(n=149)$} & $P$ values \\
\hline & $n$ & $\%$ & $n$ & $\%$ & \\
\hline \multicolumn{6}{|l|}{ (B) } \\
\hline $\mathrm{GG} / \mathrm{CC}$ & 269 & $73.50 \%$ & 109 & $73.15 \%$ & 1.0 \\
\hline GG/AC & 69 & $18.85 \%$ & 28 & $18.79 \%$ & 1.0 \\
\hline $\mathrm{AG} / \mathrm{CC}$ & 22 & $6.01 \%$ & 12 & $8.05 \%$ & 0.5 \\
\hline $\mathrm{AG} / \mathrm{AC}$ & 3 & $0.82 \%$ & 0 & $0.00 \%$ & 0.07 \\
\hline GG/AA & 3 & $0.82 \%$ & 0 & $0.00 \%$ & 0.07 \\
\hline
\end{tabular}

a $\mathrm{OR}=2.88(1.19-7.11)$

b $\mathrm{OR}=2.97(1.12-7.77)$.

c $\mathrm{OR}=0.26(0.11-0.61)$.

gene might influence significantly the risk of ALL in these children. Furthermore, Urayama et al. found statistically significant increased risk to hyperdiploid ALL with very high ORs in carriers of certain $M D R 1$ genotypes and a haplotype. For example, carrier status of 3435 TT associated with an almost 9-fold increased risk to hyperdiploid ALL. In our study with a population almost three times as large as in that study (27 versus 78 hyperdiploid ALL cases) we did not find such association, even the ORs for the corresponding genotypes were consistently, although not significantly below 1 .

One possible explanation of these inconsistencies between the studies can be the relative low numbers of patients investigated in these studies. ALL is a multifactorial disease influenced by several diverse genetic variations. The effects of these variations are usually modest and detecting them would require large number of homogenous patients from homogenous environment. Although our study involves the largest number of patients, it still has only $60 \%$ power to detect the difference found in the haplotype analysis. The other studies investigated significantly less patients, and this could raise the possibility of type 1 error. Unfortunately, it is very difficult to collect the number of ALL children with homogenous ethnicity and from similar environment required for the suitable statistical power to detect such weak genetic effects.

The other factor that can contribute to the inconsistencies between the results is the different environment. For example, Urayama et al. found that although the $M D R l$ haplotype did not influence the susceptibility to the disease when all chil- dren were considered, but non-carriers of a haplotype exposed to indoor insecticides had a 3-fold increased risk of ALL [9]. This result shows the significance of the environmental factors and the gene-environmental interaction in the susceptibility and development of multifactorial diseases, like ALL. It is very much possible that the Californian children (investigated in the other study), and Hungarian children are exposed to different environmental factors (e.g. among others different usage of insecticides) thus the gene-environmental interaction could result in different phenotype.

Although all studies investigated Caucasian patients, and the $M D R 1$ allele frequencies were similar in all cases, the different populations could also differ in genetic background which can then contribute to the discrepancies in the results.

Previously, a part of this ALL population was also investigated, whether polymorphisms or haplotypes in the MDRI gene influenced the side effects of chemotherapy [16,19]. In these studies, it was found that patients with 3435TT genotype had more frequent encephalopathy episodes and required more intravenous antimicrobial therapy during the whole intensive chemotherapy phase compared to the remaining part of the population. According to these and the present studies, the 3435TT genotype does not influence the risk to ALL in our patients, but can influence the side effects of the therapy.

In spite of decades of extensive research, the physiological role of P-gp remains not fully understood. Several toxins, including anticancer drugs belong to P-gp substrates which suggest the involvement of $\mathrm{P}$-gp in protection against toxic xenobiotics $[4,20]$. In this regard, it can be anticipated that 
genetically based or acquired alterations in P-gp activity may lead to increased exposure to toxins and by this mechanism contribute to increased risk of tumorogenesis. On the other hand, a number of studies provided convincing evidence that P-gp serves several distinct functions in regulation of apoptotic death, immune response and even stem cells [21,22,23]. These latter processes can also play some role in carcinogenesis.

Several studies investigated the effect of C3435T polymorphism on P-gp expression, activity, pharmacokinetic parameters and susceptibility to different tumors [8]. Although the results are quite inconsistent, C3435T seems to be linked with lower P-gp expression, altered substrate specifity and higher susceptibility to certain tumors [24,25]. While C3435T does not lead to an amino acid change, a recent study reports altered substrate specificity of certain MDRl haplotypes containing the $3435 \mathrm{~T}$ allele because of differences in folding as a result of translational rate differences [5]. Interestingly, the C3435T polymorphism alone did not cause altered gene expression, protein function or substrate specificity, only as a component of different haplotypes.

According to our results, in Hungarian children the individual polymorphisms and the most frequent haplotypes of the MDRl gene do not influence the susceptibility to ALL, but a rare haplotype containing the $3435 \mathrm{~T}$ allele associates with increased risk, while a rare haplotype without this allele associates with decreased risk to ALL. We have also found that some rare genotype combinations within the $M D R l$ gene occur more frequently, another one less frequently in ALL patients than in healthy controls. We believe, that owing to negative selection, there is a small possibility that frequent alleles, genotypes and haplotypes can play important role in disease susceptibility especially in children. But, because of the several potential different physiological functions of the P-gp, it is not possible to explain the role of haplotypes and genotype associations in such a complex process as disease susceptibility simply by altered specificity to some substrates. The roles of different MDRl alleles and haplotypes in childhood ALL must be tested in prospective studies in large populations considering also the gene-gene and gene-environmental interactions.

\section{Acknowledgements}

This study was financially supported by grants from the Hungarian Scientific Research Fund (T042500) and the Economic Competitiveness Operational Program, Hungary (GVOP 3.1.1-2004-05-0022/3.0).

We are grateful to all nurses, doctors and patients who took part in the study. We would like to thank Krisztina Kovács, Krisztina Staub, Dóra Lippai, Xénia Majorosi, Melinda Rácz, Veronika Galasz, Erika Tóth and Gábor Váradi for technical assistance.

Contributions. Ágnes F. Semsei: genotyping, evaluating the results, writing the paper. Dániel J. Erdélyi: organiz- ing the whole project, organizing and collection of the ALL patients. Ildikó Ungvári: statistical evaluation. Enikó Kámory: genotyping. Béla Csókay: organizing and evaluating some genotypings. Hajnalka Andrikovics: genotyping, evaluating some genotypings. Attila Tordai: organizing the collection of the control subjects, organizing some genotypings. Edit Cságoly: collection and evaluation the clinical data. András Falus: organizing the project. Gábor T. Kovács: collection and evaluation the clinical data. Csaba Szalai: organizing the laboratory work, evaluating the data, writing the paper. All of the authors read the paper, and contributed to the evaluation of the results.

\section{References}

[1] Bolufer P, Barragan E, Collado M, Cervera J, Lopez JA, Sanz MA. Influence of genetic polymorphisms on the risk of developing leukemia and on disease progression. Leuk Res 2006;30:1471-91.

[2] Juliano RL, Ling V. A surface glycoprotein modulating drug permeability in Chinese hamster ovary cell mutants. Biochim Biophys Acta 1976;455:152-62.

[3] Klimecki WT, Futscher BW, Grogan TM, Dalton WS. P-glycoprotein expression and function in circulating blood cells from normal volunteers. Blood 1994;83:2451-8.

[4] Walle UK, Walle T. Transport of the cooked-food mutagen 2-amino1-methyl-6-phenylimidazo-[4,5-b]pyridine (PhIP) across the human intestinal Caco-2 cell monolayer: role of efflux pumps. Carcinogenesis 1999;20:2153-7.

[5] Kimchi-Sarfaty C, Oh JM, Kim IW, Sauna ZE, Calcagno AM, Ambudkar SV, et al. A "silent" polymorphism in the MDR1 gene changes substrate specificity. Science 2007;315:525-8.

[6] Hoffmeyer S, Burk O, von Richter O, Arnold HP, Brockmoller J, Johne A, et al. Functional polymorphisms of the human multidrug-resistance gene: multiple sequence variations and correlation of one allele with Pglycoprotein expression and activity in vivo. Proc Natl Acad Sci USA 2000;97:3473-8.

[7] Horinouchi M, Sakaeda T, Nakamura T, Morita Y, Tamura T, Aoyama $\mathrm{N}$, et al. Significant genetic linkage of MDR1 polymorphisms at positions 3435 and 2677: functional relevance to pharmacokinetics of digoxin. Pharm Res 2002;19:1581-5.

[8] Jamroziak K, Robak T. Pharmacogenomics of MDR1/ABCB1 gene: the influence on risk and clinical outcome of haematological malignancies. Hematology 2004;9:91-105.

[9] Urayama KY, Wiencke JK, Buffler PA, Chokkalingam AP, Metayer C, Wiemels JL. MDR1 gene variants, indoor insecticide exposure, and the risk of childhood acute lymphoblastic leukemia. Cancer Epidemiol Biomarkers Prev 2007;16:1172-7.

[10] Hattori H, Suminoe A, Wada M, Koga Y, Kohno K, Okamura J, et al. Regulatory polymorphisms of multidrug resistance 1 (MDR1) gene are associated with the development of childhood acute lymphoblastic leukemia. Leuk Res 2007;31:1633-40.

[11] Doyle LA, Yang W, Abruzzo LV, Krogmann T, Gao Y, Rishi AK, et al. A multidrug resistance transporter from human MCF-7 breast cancer cells. Proc Natl Acad Sci USA 1998;95:15665-70.

[12] Mao Q, Unadkat JD. Role of the breast cancer resistance protein (ABCG2) in drug transport. AAPS J 2005;7:E118-33.

[13] Suzuki M, Suzuki H, Sugimoto Y, Sugiyama Y. ABCG2 transports sulfated conjugates of steroids and xenobiotics. J Biol Chem 2003;278:22644-9.

[14] Krishnamurthy P, Schuetz JD. Role of ABCG2/BCRP in biology and medicine. Annu Rev Pharmacol Toxicol 2006;46:381-410.

[15] Gwee PC, Tang K, Chua JM, Lee EJ, Chong SS, Lee CG. Simultaneous genotyping of seven single-nucleotide polymorphisms in the 
MDR1 gene by single-tube multiplex minisequencing. Clin Chem 2003;49:672-6.

[16] Erdelyi DJ, Kamory E, Zalka A, Semsei AF, Csokay B, Andrikovics H, et al. The role of ABC-transporter gene polymorphisms in chemotherapy induced immunosuppression, a retrospective study in childhood acute lymphoblastic leukaemia. Cell Immunol 2006;244:121-4.

[17] Szilvasi A, Andrikovics H, Kalmar L, Bors A, Tordai A. Asymmetric PCR increases efficiency of melting peak analysis on the LightCycler. Clin Biochem 2005;38:727-30.

[18] Barrett JC, Fry B, Maller J, Daly MJ. Haploview: analysis and visualization of LD and haplotype maps. Bioinformatics 2005;21:263-5.

[19] Erdélyi DJ, Kámory E, Csókay B, Andrikovics H, Tordai A, Kiss C, et al. Synergistic interaction of ABCB1 and ABCG2 polymorphisms predicts the prevalence of toxic encephalopathy during anticancer chemotherapy. Pharmacogenomics J 2007 [Epub ahead of print].

[20] Penny JI, Campbell FC. Active transport of benzo[a]pyrene in apical membrane vesicles from normal human intestinal epithelium. Biochim Biophys Acta 1994;1226:232-6.
[21] Smyth MJ, Krasovskis E, Sutton VR, Johnstone RW. The drug efflux protein, P-glycoprotein, additionally protects drug-resistant tumor cells from multiple forms of caspase-dependent apoptosis. Proc Natl Acad Sci USA 1998;95:7024-9.

[22] Randolph GJ, Beaulieu S, Pope M, Sugawara I, Hoffman L, Steinman $\mathrm{RM}$, et al. A physiologic function for p-glycoprotein (MDR-1) during the migration of dendritic cells from skin via afferent lymphatic vessels. Proc Natl Acad Sci USA 1998;95:6924-9.

[23] Bunting KD. ABC transporters as phenotypic markers and functional regulators of stem cells. Stem Cells 2002;20:11-20.

[24] Potocnik U, Ravnik-Glavac M, Glavac D. Functional MDR1 polymorphisms (G2677T and C3435T) and TCF4 mutations in colorectal tumors with high microsatellite instability. Cell Mol Biol Lett 2002;7:92-5.

[25] Schwab M, Schaeffeler E, Marx C, Fromm MF, Kaskas B, Metzler $\mathrm{J}$, et al. Association between the C3435T MDR1 gene polymorphism and susceptibility for ulcerative colitis. Gastroenterology 2003;124:2633. 